\title{
Validation of the MEDFICTS dietary questionnaire: A clinical tool to assess adherence to American Heart Association dietary fat intake guidelines
}

\author{
Allen J Taylor*1, Henry Wong ${ }^{4}$, Karen Wish ${ }^{3}$, Jon Carrow ${ }^{4}$, Debulon Bell ${ }^{4}$, \\ Jody Bindeman ${ }^{4}$, Tammy Watkins ${ }^{4}$, Trudy Lehmann ${ }^{4}$, Saroj Bhattarai ${ }^{4}$ and \\ Patrick G O'Malley²
} \begin{abstract}
Lanham, MD, USA
Email: Allen J Taylor* - allen.taylor@na.amedd.army.mil; Henry Wong -yu.wong@na.amedd.army.mil; Karen Wish - karen.wish@se.amedd.army.mil; Jon Carrow - harold.carrow@na.amedd.army.mil;

Debulon Bell - allen.taylor@na.amedd.army.mil; Jody Bindeman - jody.bindeman@na.amedd.army.mil;

Tammy Watkins - tammy.watkins@na.amedd.army.mil; Trudy Lehmann - trudy.lehmann@na.amedd.army.mil;

Saroj Bhattarai - saroj.bhattarai@na.amedd.army.mil; Patrick G O'Malley - patrick.omalley@na.amedd.army.mil

* Corresponding author
\end{abstract}

Address: ${ }^{1}$ Cardiology Service, Walter Reed Army Medical Center, Washington, DC, USA, ${ }^{2}$ Dwight D. Eisenhower Army Medical Center, Ft. Gordon, GA, USA, ${ }^{3}$ General Internal Medicine Service, Walter Reed Army Medical Center, Washington, DC, USA and ${ }^{4}$ Systems Assessment \& Research, Inc.,

Published: 13 June 2003

Nutrition Journal 2003, 2:4

This article is available from: http://www.nutritionj.com/content/2/l/4

(C) 2003 Taylor et al; licensee BioMed Central Ltd. This is an Open Access article: verbatim copying and redistribution of this article are permitted in all media for any purpose, provided this notice is preserved along with the article's original URL.
Received: 28 October 2002

Accepted: 13 June 2003

\begin{abstract}
Background: Dietary assessment tools are often too long, difficult to quantify, expensive to process, and largely used for research purposes. A rapid and accurate assessment of dietary fat intake is critically important in clinical decision-making regarding dietary advice for coronary risk reduction. We assessed the validity of the MEDFICTS (MF) questionnaire, a brief instrument developed to assess fat intake according to the American Heart Association (AHA) dietary "steps".
\end{abstract}

Methods: We surveyed 164 active-duty US Army personnel without known coronary artery disease at their intake interview for a primary prevention cardiac intervention trial using the Block food frequency (FFQ) and MF questionnaires. Both surveys were completed on the same intake visit and independently scored. Correlations between each tools' assessment of fat intake, the agreement in AHA step categorization of dietary quality with each tool, and the test characteristics of the MF using the FFQ as the gold standard were assessed.

Results: Subjects consumed a mean of $36.0 \pm 13.0 \%$ of their total calories as fat, which included saturated fat consumption of $13.0 \pm 0.4 \%$. The majority of subjects (I25/I64; 76.2\%) had a high fat (worse than AHA Step I) diet. There were significant correlations between the MF and the FFQ for the intake of total fat $(r=0.52, P<0.000 I)$ and saturated fat $(r=0.52, P<0.000 I)$. Despite these modest correlations, the currently recommended MF cutpoints correctly identified only 29 of 125 (23.3\%) high fat (worse than AHA Step I) diets. Overall agreement for the AHA diet step between the FFQ and MF (using the previously proposed MF score cutoffs of 0-39 [AHA Step 2], 40-70 [Step I], and >70 [high fat diet]) was negligible (kappa statistic $=0.036$ ). The MF was accurate at the extremes of fat intake, but could not reliably identify the 3 AHA dietary classifications. Alternative MF cutpoints of $<30$ (Step 2), 30-50 (Step I), and >50 (high fat diet) were highly sensitive (96\%), but had low specificity (46\%) for a high fat diet. ROC curve analysis identified that 
a MF score cutoff of 38 provided optimal sensitivity $75 \%$ and specificity $72 \%$, and had modest agreement $(\mathrm{kappa}=0.39, \mathrm{P}<0.00 \mathrm{I})$ with the FFQ for the identification of subjects with a high fat diet.

Conclusions: The MEDFICTS questionnaire is most suitable as a tool to identify high fat diets, rather than discriminate AHA Step I and Step 2 diets. Currently recommended MEDFICTS cutpoints are too high, leading to overestimation of dietary quality. A cutpoint of 38 appears to be providing optimal identification of patients who do not meet AHA dietary guidelines for fat intake.

\section{Background}

Dietary fat intake is a risk factor for coronary heart disease and the modification of dietary habits is important for the prevention of cardiovascular disease. The assessment of dietary fat intake is a critically important first step in clinical decision-making regarding dietary and pharmacotherapeutic advice on coronary risk reduction. Thus, a rapid and accurate tool to assess dietary fat intake would be a clinically useful screening tool for physicians to counsel patients about diet and coronary risk reduction.

Commonly used dietary assessment tools include dietary history, 24-hour recall, seven-day recall, seven-day record, and food frequency questionnaire. [1-7] Impediments to more widespread clinical use of these tools include their length, and the difficulty and expense of their analysis. Furthermore, nutrition researchers tend to focus on a method's ability to yield precise and accurate measurement of a nutrient rather than to evaluate whether a tool can simply and quickly identify an individual's distribution or pattern of food intake. We compared the accuracy of the MEDFICTS (MF) questionnaire, [8] a brief instrument developed to assess fat intake according to the American Heart Association (AHA) dietary "steps, "[9,10] to the standardized Block Food Frequency Questionnaire $[11,12]$ (FFQ) in a sample of active duty US Army personnel without known coronary artery disease.

\section{Methods}

Subjects

This study contains data from 164 active-duty U.S. Army personnel who completed both the MF and Block FFQ. Subjects completed the surveys during the same intake interview for a primary prevention intervention trial - the Prospective Army Coronary Calcium (PACC) Study. The study was approved by the Department of Clinical Investigation of the Walter Reed Army Medical Center.

The methods of the PACC Study have been previously described.[13] Briefly, since October 1998, active-duty Army personnel from 39 through 45 of age who were stationed in the National Capital Area of the Walter Reed Health Care System were recruited at the time of a periodic, Army-mandated physical examination. Persons who had a history of coronary heart disease or who reported a history of angina pectoris on the Rose questionnaire were ineligible. Between October 26, 1998 and November 4, 1999, 705 eligible participants were screened and 630 provided written informed consent to undergo electron beam computed tomography (EBCT) in addition to the required physical examination procedures. A subset of these subjects also volunteered to participate in a randomized, controlled trial to assess the impact of the knowledge of EBCT results and nurse-based case management on risk factor modification. The 164 subjects included in this dietary assessment study are a consecutive sample of subjects who both consented to participate in the randomized controlled trial and who also completed the MF and Block FFQ questionnaires. Demographic characteristics of the study participants are shown in Table 1.

\section{Dietary Assessment Tools}

Each participant filled out a series of questionnaires that included the 2 dietary assessment tools: the validated and reduced version of the Block FFQ and the full version of the MF. The reduced version of Block FFQ is a validated food survey that contains 60 food items and is intended to capture all nutrients in the diet including dietary fat intake. The survey requires approximately 15 minutes to self-administer, however, the survey requires a relatively detailed analysis, thus the results are not immediately available for patient counseling. This study focuses only on those variables from the Block FFQ that are relevant to dietary fat intake within the dietary guidelines of the American Heart Association (AHA). This includes total calories, percentage of calories from fat and saturated fat, and cholesterol intake.

The MF questionnaire was specifically designed to evaluate patient adherence to the National Cholesterol Education Program (NCEP) Step 1 and Step 2 diets adopted by the American Heart Association (AHA). The main objective of these dietary steps is incrementally reduce coronary heart disease risk through diet-induced reduction in LDL cholesterol. Both the AHA Step 1 and 2 diets focus on reducing total fat to $30 \%$ or less of daily energy, and progressively reducing saturated fat and cholesterol intake (Step 1: 7-10\% of energy from saturated fat and $<300 \mathrm{mg}$ cholesterol; Step 2: $<7 \%$ of energy from saturated fat and $<200 \mathrm{mg}$ cholesterol). The AHA Step 1 diet is recom- 
Table I: Demographic Characteristics and Select Cardiac Risk Factors of the PACC Participants (N = I64)

\begin{tabular}{ll}
\hline Variable & Value* \\
\hline Demographic Characteristics: & 79.9 \\
Male gender (\%) & $42 \pm 2$ \\
Age (yr) & 65.9 \\
Caucasian (\%) & 78.4 \\
College educated (\%) & \\
Cardiac Risk Factors: & $203 \pm 34$ \\
Total cholesterol (mg/dl) & $130 \pm 33$ \\
LDL (mg/dl) & $52 \pm 14$ \\
HDL (mg/dl) & $117 \pm 64$ \\
Triglycerides (mg/dl) & $27 \pm 4$ \\
BMI & $92 \pm 10$ \\
Waist girth (cm) & \\
\hline
\end{tabular}

*Plus-minus values are means and standard deviations.

mended for all healthy persons for the prevention of coronary heart disease, and is recommended to precede pharmacotherapy of LDL cholesterol. The Step 2 diet is recommended to further reduce LDL cholesterol for patients that have already achieved their Step 1 dietary goals. Additionally, the Step 2 diet is the initially recommended diet for patients with either a high-risk cholesterol level $(>240 \mathrm{mg} / \mathrm{dL})$ or with known coronary heart disease.

The MEDFICTS questionnaire is a brief instrument consisting of 8 food categories: Meats, Eggs, Dairy, Fried foods, fat In baked goods, Convenience foods, fats added at the Table, and Snacks. The first column of the questionnaire addresses each of these food categories. Within each category, food items are assigned to either group 1 (desirable) or group 2 (undesirable) based upon total fat content. Numeric values are assigned to each food group, with weightings based upon weekly consumption and serving size. The questionnaire is scored using totaling the quality-adjusted intake quantity yielding a possible range of scores from 0 to 216 points. Lower MF scores indicate diets containing less dietary fat. Prior validation literature indicated that a score of $<40$ points is consistent with a Step 2 diet, a score between 40 to 69 is consistent with a Step 1 diet, and a score of $>70$ is considered as high fat diet. The MF can be self-administered in 3 to 5 minutes, and scored by the healthcare provider in approximately 2 minutes. Thus, the MF is an efficient tool enabling health care providers to quickly assess the adherence of patients to the fat components of a Step 1 or 2 diet, and identify patients consuming a diet higher in total fat, saturated fat, and cholesterol.

\section{Statistical Analysis}

The two dietary questionnaires were independently scored. The reduced version Block FFQ was coded and analyzed by the same investigator to provide consistency in scoring. The validation of MF scores with Block FFQ dietary variables (percent of fat, percentage of saturated fat, and cholesterol level) was evaluated by Spearman's rho, because both dietary scores were not normally distributed. The level of inter-test agreement between the two dietary instruments was assessed using the kappa statistic. Receiver operating characteristic (ROC) Curve analysis was applied to measure the sensitivity and specificity of the alternative MF cutpoints. All analyses were performed using SPSS for Windows (v 10.05, Chicago, IL). Data are presented as mean $\pm \mathrm{SD}$. A two-tailed $\mathrm{P}$ value of $\leq 0.05$ was considered to indicate statistical significance.

\section{Results}

Mean daily intake values included total fat (\% calories) of $35.5 \pm 13.0 \%$, saturated fat $13.0 \pm 0.4 \%$, and cholesterol $267 \pm 283 \mathrm{mg} / \mathrm{dL}$. These data, obtained with the Block FFQ, indicated that $76.2 \%$ of the participants had a high fat (worse than the AHA Step 1) diet. In contrast, the MF questionnaire identified only $17.7 \%$ of the group as having a high fat diet (Table 2). The other subjects (82.3\%) were indicated as having a low fat diet, and were approximately equally divided between AHA Step 1 and 2 diets.

There were significant correlations between the MF and Block FFQ for the percentage intake of fat $(\mathrm{r}=0.52, \mathrm{P}<$ $0.0001)$, saturated fat $(\mathrm{r}=0.52, \mathrm{P}<0.0001)$, and cholesterol $(\mathrm{r}=0.55, \mathrm{P}<0.0001)$. Subjects within the different MF diet categories did significantly differ with respect to fat intake (Table 3). Despite these modest correlations, the MF (based on the currently-recommended MF score cutoffs of 0-39 for Step 2, 40-70 for Step 1, and >70 for 
Table 2: Dietary data for the study group

\begin{tabular}{|c|c|c|c|}
\hline Dietary Data & Male $(N=|3|)$ & Female $(\mathbf{N}=33)$ & Total $(N=164)$ \\
\hline \multicolumn{4}{|l|}{ MEDFICTS Data: } \\
\hline \multicolumn{4}{|c|}{ Diet Group Distribution (\%)* } \\
\hline High fat diet & 19.8 & 9.1 & 17.7 \\
\hline Step I diet & 44.3 & 39.4 & 43.3 \\
\hline Step 2 diet & 35.9 & 51.5 & 39.0 \\
\hline Total MEDFICTS Score & $49 \pm 27^{* *}$ & $41 \pm 27$ & $48 \pm 27$ \\
\hline \multicolumn{4}{|l|}{ Block Dietary Data: } \\
\hline Total Calories & $1576 \pm 674$ & $|32| \pm 530$ & $1525 \pm 654$ \\
\hline$\%$ fat & $35.8 \pm 14.0$ & $34.4 \pm 1.0$ & $35.5 \pm 13.0$ \\
\hline$\%$ saturated fat & $12.7 \pm 0.4$ & $12.2 \pm 0.4$ & $12.6 \pm 0.4$ \\
\hline Cholesterol (mg/dl) & $283 \pm 311$ & $201 \pm 98$ & $267 \pm 283$ \\
\hline
\end{tabular}

* MEDFICTS Diet Groups: High fat diet group: MEDFICTS score $>70$ Step I diet group: MEDFICTS score: $40-70<30 \%$ fat, $<10 \%$ saturated fat, $<300 \mathrm{mg} / \mathrm{dl}$ cholesterol Step 2 diet group: MEDFICTS score $<40<30 \% \mathrm{fat},<7 \%$ saturated fat, $<200 \mathrm{mg} / \mathrm{dl}$ cholesterol Data shown are means \pm standard deviations.

Table 3: Comparisons of daily caloric, fat and cholesterol intake within MEDFICTS Diet Groups

\begin{tabular}{|c|c|c|c|c|c|}
\hline $\begin{array}{l}\text { Block Dietary } \\
\text { Variable }\end{array}$ & $\begin{array}{l}\text { High Fat } \\
\text { Diet }\end{array}$ & $\begin{array}{l}\text { Step I } \\
\text { Diet }\end{array}$ & $\begin{array}{l}\text { Step } 2 \\
\text { Diet }\end{array}$ & $\begin{array}{l}\text { ANOVA } \\
F\end{array}$ & Sig. \\
\hline Total calories & 1980 & 1540 & 1302 & 12.3 & .0001 \\
\hline$\%$ fat & 40.9 & 38 & 30.3 & 10.1 & .0001 \\
\hline$\%$ saturated fat & 15.7 & 13.1 & 10.6 & 22.1 & .0001 \\
\hline Cholesterol & 351 & 309 & 181 & 5.3 & .006 \\
\hline
\end{tabular}

Table 4: MEDFICTS Diet Groups and AHA Diet Steps Crosstabulation

\begin{tabular}{|c|c|c|c|c|}
\hline \multirow{2}{*}{$\begin{array}{l}\text { MEDFICTS Diet } \\
\text { Groups }\end{array}$} & \multicolumn{4}{|c|}{ AHA Diet Steps } \\
\hline & High Fat & Step I & Step 2 & Total \\
\hline High Fat Diet & $29(100.0 \%) *(23.2 \%)^{* *}$ & & & $29(100.0 \%)(17.7 \%)$ \\
\hline Step I Diet & 62 (87.3\%) (49.6\%) & 5 (7.0\%) (19.2\%) & 4 (5.6\%) (30.8\%) & 71 (100.0\%) (43.3\%) \\
\hline Step 2 Diet & 34 (53.1\%) (27.2\%) & $21(32.8 \%)(80.8 \%)$ & $9(14.1 \%)(69.2 \%)$ & 64 (I00.0\%) (39.0\%) \\
\hline Total & $125(76.2 \%)(100.0 \%)$ & $26(15.9 \%)(100.0 \%)$ & $13(7.9 \%)(100.0 \%)$ & $164(100.0 \%)(100.0 \%)$ \\
\hline
\end{tabular}

* \% within MEDFICTS diet groups. ** \% within AHA diet steps.

high fat diets) correctly identified only 29 of 125 (23.3\%) high fat (worse than AHA Step 1) diets, and 19.2\% of Step 1 diets (Table 4). The overall agreement for the AHA diet steps between the Block FFQ and MF was negligible (kappa statistics $=0.036$ ). The MF was accurate at the extremes of fat intake, but could not reliably separate patient groups into 3 AHA dietary classifications.

Exploratory analysis showed that alternative MF cutpoints of <30 (Step 2), 30-50 (Step 1), and >50 (high fat diet) were highly sensitive $(96 \%)$, but had low specificity
(46\%) for a high fat diet. Receiver operating characteristic (ROC) curve analysis showed that a single MF score cutoff of 38 yielded optimal sensitivity of $75 \%$ and specificity of $72 \%$ (Figure 1), and had modest agreement (kappa statistics $=0.39, \mathrm{P}<0.001)$ with the Block FFQ for the identification of patients with a high fat diet (Figure).

\section{Discussion}

The effective identification of patients requiring dietary intervention for the reduction of fat intake requires an accurate, efficient, clinically applicable dietary assessment 


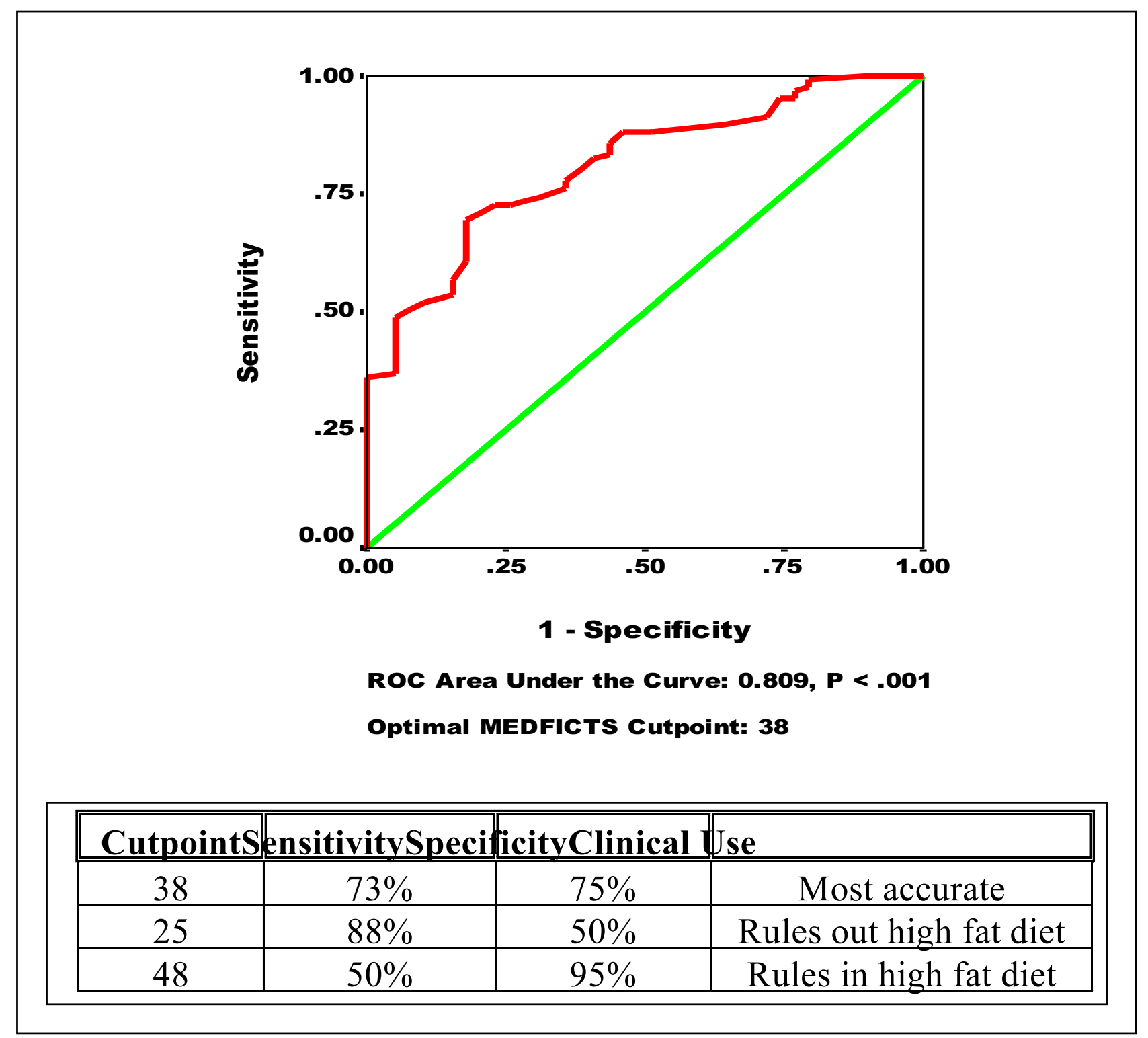

Figure I

ROC curve showing the relationship between AHA Diet Steps and MEDFICTS Diet Groups at a MEDFICTS score cutpoint of 38.

tool. In this study, we compared the accuracy of the MEDFICTS dietary survey to the Block FFQ for the identification of compliance with the AHA dietary guidelines for fat intake. These data indicate that the MF questionnaire has moderate accuracy for the semi-quantitation of dietary fat and saturated fat intake. However, the currently-recommended MF cutpoints resulted in marked over-estimation of dietary quality, including an inability to accurately detect high fat diets. Furthermore, this tool does not appear to have adequate test characteristics to accurately discriminate Step 1 and Step 2 diets. This is likely due to the small differences in fat intake between these 2 diets, and the relatively crude nature of the MF survey. However, our data suggest that a revised cutpoint of 38 for the MF questionnaire resulted in modest accuracy for the detection of a high fat diet. 
Beyond ease of administration, an additional advantage of the MF survey may be its utility as a tool for dietary education and lifestyle modification. The content and design of the MF is clear and simple, but comprehensive enough to categorically provide dietary fat intake guidance for a wide variety of food goods. The survey provides rapid depiction of the greatest contributors to dietary fat intake within a given patient's diet, and suggests strategies (alternative food choices, or reduced portion size) for the reduction of dietary fat. However, whether the MF would serve as a useful tool to guide dietary modification will require further study.

\section{Conclusions}

The MF questionnaire is an efficient tool that can be used by health professionals to quickly assess the dietary fat intake. It provides immediate identification of patients consuming a diet higher in total fat, saturated fat, and cholesterol than currently recommended by the American Heart Association. However, the current recommended cutpoints of the MEDFICTS questionnaire are unable to discriminate the AHA Step 1 and Step 2 diets. Current MEDFICTS cutpoints are too high, leading to overestimation of dietary quality. A cutpoint of 38 appears to be providing optimal identification of patients who do not meet AHA dietary guidelines for fat intake.

Allen J. Taylor- Project design, data analysis, manuscript preparation Henry Wong- Project design, data analysis, manuscript preparation Karen Wish- Primary data analysis, manuscript preparation Jon Carrow- Data collection, data analysis, manuscript preparation Debulon Bell- Data collection, data analysis, manuscript preparation Jody Bindeman- Data collection, data analysis, manuscript preparation Tammy Watkins- Data collection, data analysis, manuscript preparation Trudy Lehmann- Data collection, data analysis, manuscript preparation Saroj Bhattarai- Data management, data analysis, manuscript preparation Patrick G. O'Malley- Project design, data analysis, manuscript preparation

\section{References}

I. Beaton GH, Milner J, Corey P, McGuire V, Cousins M and Stewart E: Sources of variance in 24-hour dietary recall data: implications for nutrition study design and interpretation $\mathrm{Am}$ J Clin Nutr 1979, 32:2546-2549.

2. Block G, Hartman AM, Dresser CM, Carroll MD, Gannon J and Gardner L: A data-based approach to diet questionnaire design and testing Am J Epidemiol 1986, I 24:453-469.

3. Briefel RR, Flegal KM, Winn DM, Loria CM, Johnson CL and Sempos $C T$ : Assessing the nation's diet: limitations of the food frequency questionnaire $J$ Am Diet Assoc 1992, 92:959-962.

4. Hankin JH, Nomura AM, Lee J, Hirohata T and Kolonel LN: Reproducibility of a diet history questionnaire in a case-control study of breast cancer Am J Clin Nutr 1983, 37:981-985.

5. Neuhouser ML, Kristal AR, McLerran D, Patterson RE and Atkinson $\mathrm{J}$ : Validity of short food frequency questionnaires used in cancer chemoprevention trials: results from the Prostate Cancer Prevention Trial Cancer Epidemiol Biomarkers Prev 1999, 8:72I725.
6. Olendzki B, Hurley TG, Hebert JR, Ellis S, Merriam PA and Luippold $R$ : Comparing food intake using the Dietary Risk Assessment with multiple 24-hour dietary recalls and the 7-Day Dietary Recall J Am Diet Assoc 1999, 99: 1433-1439.

7. Gersovitz M, Madden JP and Smiciklas-Wright H: Validity of the 24hr. dietary recall and seven-day record for group comparisons J Am Diet Assoc 1978, 73:48-55.

8. Kris-Etherton P, Eissenstat $B$, Jaax $S$, Srinath $U$, Scott $L$ and Rader J: Validation for MEDFICTS, a dietary assessment instrument for evaluating adherence to total and saturated fat recommendations of the National Cholesterol Education Program Step I and Step 2 diets J Am Diet Assoc 200 I, I 0 I:8 I-86.

9. Krauss RM, Eckel RH, Howard B, Appel LJ, Daniels SR and Deckelbaum RJ: AHA Dietary Guidelines: revision 2000: A statement for healthcare professionals from the Nutrition Committee of the American Heart Association Circulation 2000, 102:22842299.

10. National Cholesterol Education Program. Second Report of the Expert Panel on Detection, Evaluation, and Treatment of High Blood Cholesterol in Adults (Adult Treatment Panel II) Circulation 1994, 89: I333-1445.

II. Block G, Hartman AM and Naughton D: A reduced dietary questionnaire: development and validation Epidemiology 1990, I:5864.

12. Potischman N, Carroll RJ, Iturria SJ, Mittl B, Curtin J and Thompson FE: Comparison of the $\mathbf{6 0}$-and 100 -item $\mathrm{NCl}$-block questionnaires with validation data Nutr Cancer 1999, 34:70-75.

13. O'Malley PG, Taylor AJ, Gibbons RV, Feuerstein IM, Jones DL and Vernalis M: Rationale and design of the Prospective Army Coronary Calcium (PACC) Study: utility of electron beam computed tomography as a screening test for coronary artery disease and as an intervention for risk factor modification among young, asymptomatic, active-duty United States Army Personnel Am Heart J 1999, 137:932-941.

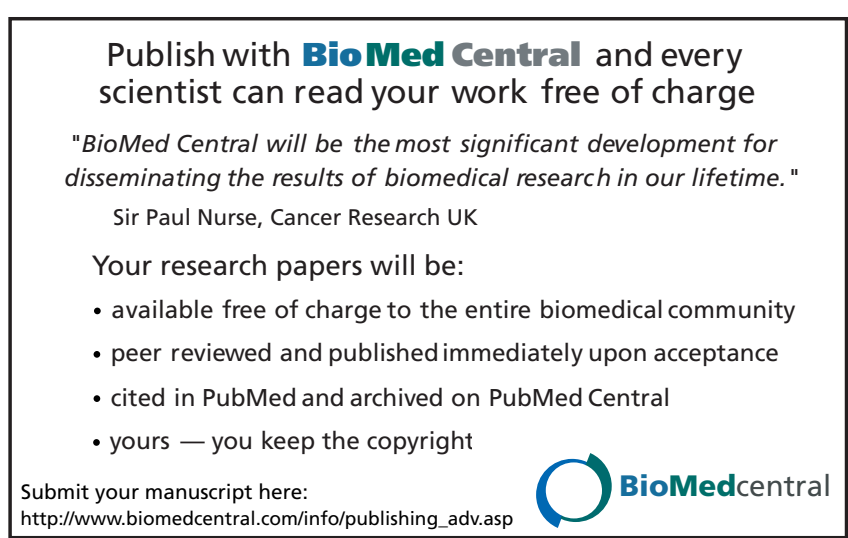

